\title{
Transcriptome-wide characterization and functional analysis of Xyloglucan endo- transglycosylase/hydrolase (XTH) gene family of Salicornia europaea L. under salinity and drought stress
}

Richard John Tiika ${ }^{1,2}$, Jia Wei ${ }^{1,2}$, Guangxin Cui ${ }^{1}$, Yanjun Ma ${ }^{2}$, Hongshan Yang ${ }^{1 *}$ and Huirong Duan ${ }^{1 *}$

\begin{abstract}
Background: Salicornia europaea is a halophyte that has a very pronounced salt tolerance. As a cell wall manipulating enzyme, xyloglucan endotransglycosylase/hydrolase (XTH) plays an important role in plant resistance to abiotic stress. However, no systematic study of the XTH gene family in S. europaea is well known. PacBio Iso-Seq transcriptome sequence data were used for bioinformatics and gene expression analysis using real-time quantitative polymerase chain reaction (RT-qPCR).

Results: Transcriptome sequencing (PacBio Iso-Seq system) generated 16,465,671 sub-reads and after quality control of Iso-Seq, 29,520 isoforms were obtained with an average length of $2112 \mathrm{bp}$. A total of 24,869 unigenes, with $98 \%$ of which were obtained using coding sequences (CDSs), and 6398 possible transcription factors (TFs) were identified. Thirty-five (35) non-redundant potential SeXTH proteins were identified in S. europaea and categorized into group I/II and group III based on their genetic relatedness. Prediction of the conserved motif revealed that the $D E(I / L / F / N) D F(I)$ EFLG domain was conserved in the S. europaea proteins and a potential N-linked glycosylation domain $N(T) V(R / L / T / I)$ $\mathrm{T}(\mathrm{S} / \mathrm{K} / \mathrm{R} / \mathrm{F} / \mathrm{P}) \mathrm{G}$ was also located near the catalytic residues. All SeXTH genes exhibited discrete expression patterns in different tissues, at different times, and under different stresses. For example, 27 and 15 SeXTH genes were positively expressed under salt stress in shoots and roots at $200 \mathrm{mM} \mathrm{NaCl}$ in $24 \mathrm{~h}$, and $34 \mathrm{SeXTH}$ genes were also positively regulated under $48 \mathrm{~h}$ of drought stress in shoots and roots. This indicates their function in adaptation to salt and drought stress.
\end{abstract}

Conclusion: The present study discovered SeXTH gene family traits that are potential stress resistance regulators in S. europaea, and this provides a basis for future functional diversity research.

Keywords: Salicornia europaea, PacBio Iso-Seq, XTH gene family, Salinity, Drought

*Correspondence: yanghsh123@126.com; duanhuirong@caas.cn 1 Lanzhou Institute of Husbandry and Pharmaceutical Science, Chinese Academy of Agricultural Sciences, Lanzhou, China

Full list of author information is available at the end of the article

\section{Background}

Plants regularly face numerous environmental discrepancies that include abiotic and biotic stresses, and abiotic stresses tend to occur frequently in their life cycle. Salinity stress and drought including low temperature are serious problems for plant growth and productivity 
as their full genetic potential is prevented by these harsh environmental factors [1, 2]. Salinity is one of the most detrimental factors limiting plant growth and leading to nutritional limitations by reducing the absorption of calcium, nitrate, potassium and phosphorus and causing osmotic stress [3, 4]. Drought is a gradual soil water depletion and potentially a major source of stress that can suppress crop growth and it is responsible for significant yield losses in agricultural crops $[1,5]$. In response to abiotic stresses such as dehydration and excessive osmotic stress, plants resort to numerous adaptive strategies. These adaptive mechanisms involve changes in physiological and biochemical processes [6]. Consequently, most research on water stress signaling has focused on salt stress because plant responses to salt and drought stress are closely linked and signaling pathways overlap [2]. Many genes induced by salt and drought stress are part of a larger sequence of molecular networks and likely play important roles in environmental stress responses. These genes are involved in a variety of cellular and physiological function, including signal recognition and transmission, photosynthesis and energy metabolism, membrane transport, and protein production [7-11]. Numerous essential genes involved in multiple molecular pathways, such as AtSOS1, AtNHX1, AtHKT1;1, and PutHKT2;1, appear to be involved in plant responses to environmental stress [12-15]. Nevertheless, very few genes for salt and drought tolerance have been found so far, and most research on plant stress tolerance has focused on model plants such as Arabidopsis thaliana, Oryza sativa, as well as Nicotiana tabacum $[16,17]$.

Salicornia europaea, a succulent halophyte belonging to the family of Amaranthaceae, has many common names: Glasswort, Marsh samphire, and Saltwort. From available literature, this plant is one of the most salt-tolerant plants in the world [18]. As a result of evolutionary adaptation to harsh environments in unfavorable seasons, it exhibits very distinct salt and water tolerance abilities [19]. The optimal growth salinity of S. europaea is $200 \mathrm{mM}$ and can tolerate soil concentrations greater than $1000 \mathrm{mM}[3,4,20,21]$. S. europaea is ideal for cultivation to desalinate saline soils in extremely saline environments [22]. This halophyte can also be used for the development of biofuel precursors [23, 24] and as a source of secondary metabolites [25]. It is not only an important economic plant but also a suitable model plant for the identification of genes involved in abiotic stress tolerance mechanisms. Recently, salt tolerance processes and the accumulation of high salt concentrations in shoots of S. europaea have been studied by modifying proteomic signaling pathways under salt stress and identifying some genes related to salt tolerance $[3,17]$. Although to our knowledge, S. europaea is one of the most salt-tolerant halophytes, only a limited number of genes of this plant have been identified and characterized under environmental stress [26, 27]. Therefore, it was very important to perform a comprehensive transcriptomic analysis of the $X T H$ gene family under drought and salt stress. Xyloglucan endotransglycosylase/hydrolase (XTH) is one of the most important enzymes involved in biological processes $[28,29]$. The XTH is a cell wall manipulating enzyme encoded in several genes, belonging to a group of glycoside hydrolase 16 (GH16) family [30]. It is involved in various physiological and biological processes, mainly plant growth and resistance to stress [31]. XTH typically perform two distinct catalytic activities: xyloglucan endo-hydrolase (XEH) and xyloglucan endo-transglycosylase (XET), with different influences on xyloglucan: XET action results in non-hydrolytic cleavage and shortening of the xyloglucan chain, whereas XET causes irreversible chain shortening $[29,31]$. The highly conserved GH16 domain of XET (GH16-XET) shares XTH proteins with a specific ExDxE motif, which is thought to be the catalytic site for both XET and XEH activities. Thus, it contains the major $\mathrm{C}$-terminal domain of XET (C-XET), which distinguishes the XTH members from all other GH16 subfamilies [32, 33]. The $X T H$ subfamily is divided into three main groups (groups I/II and III), with XET activity being particularly pronounced in groups I and II, and group III being divided into two subgroups: IIIA and IIIB [34]. While group IIIB exhibited high XET activity, group IIIA showed prominent XEH activity $[35,36]$. The expansion of the XTH family based on sequence similarity extends an ancestral group to different organisms [37].

Using publicly available datasets, a growing number of $X T H$ genes have been identified [34]. For instance, $A$. thaliana (33), O. sativa (29), Solanum lycopersicum (25), N. tabacum (56), Glycine max (61), and Hordeum vulgare (24) have been identified as potential XTH members [17, $35,36,38-40]$. The $X T H$ gene has recently been shown to be of particular interest as unique gene members have been identified that influence plant responses to abiotic stresses [38, 40-43]. For example, CaXTH3 from Capsicum annuum was found to be highly expressed in transgenic $A$. thaliana lines and to confer increased resistance to salt and drought stress [40, 43]. MtXTH3 was strongly up-regulated in Medicago truncatula at higher $\mathrm{NaCl}$ concentration [36]. In A. thaliana, AtXTH14, - 15, and - 31 showed significantly reduced expression when exposed to aluminum stress, especially AtXTH31 [43].

RNA sequencing (RNA-Seq) is a promising application of next-generation sequencing that has been successfully used for whole transcriptome analysis in most nonmodel plants that lack a reference genome [44-46]. Using this method, researchers can identify transcriptome 
structures, novel transcripts, genes that are differentially expressed, alternative splicing and genetic variants [47]. Short-read sequencing using the Illumina platform is a powerful method for quantifying gene expression. However, the limitations of short-read sequencing lead to a number of computational challenges and hamper transcript reconstruction and splicing event detection. In recent years, an increasing number of full-length Pac-Bio transcriptomes have been generated. The PacBio Iso-Seq (isoform sequencing) platform yields long reads often up to $10 \mathrm{~kb}$, which enables accurate reconstruction of fulllength splice variants $[45,48-50]$. Due to the limitation of genomic data in S. europaea, only transcriptome data are publicly available, but these are Illumina sequencing transcriptome data $[16,24,51]$, thus the PacBio Iso-Seq platform was used in this study.

Here, we used PacBio Iso-Seq to identify $X T H$ genes of $S$. europaea associated with abiotic stress and performed some bioinformatics studies. To explore the possible involvement of $X T H$ genes responding to $\mathrm{NaCl}$ and drought stress, the $S$. europaea XTH genes were exposed to salinity and drought stress. Expression of all identified SeXTH genes was validated by RT-qPCR. The dataset provides a comprehensive list of $\mathrm{SeXTH}$ genes and an overview of their dynamic expression patterns and their potential role in controlling plant resistance to abiotic stress. This work provides important insights into the functional role of $X T H$ genes in S. europaea under stress conditions.

\section{Methods}

\section{Plant materials}

Wild seeds of S. europaea were collected from swampy areas of Liangcao Village, Jingtai County, Baiyin City, Gansu Province in China $\left(37^{\circ} 21^{\prime} 2^{\prime \prime} \mathrm{N}, 104^{\circ} 5^{\prime} 28^{\prime \prime} \mathrm{W}\right)$. It is a widely distributed wild plant in Jingtai, thus collecting for scientific research in Gansu Province is not restricted. The voucher specimen was formally identified by a plant taxonomist, Fanglan He of Gansu Desert Control Research Institute, and kept in Lanzhou Institute of Husbandry and Pharmaceutical Science Herbarium (CYSLSHrDuan20171130). The plant material collections and experimental research complied with local legislation, national and international guidelines.

Seeds were surface sterilized, washed, and grown for 3 $\mathrm{d}$ in Petri-dish under darkness. The plantlets were transferred to containers of sterilized sand and soaked in $1 / 2$ Hoagland nutrient solution after germination. The plantlets were grown in a growth chamber at $25 / 22^{\circ} \mathrm{C}$ with $65 \%$ relative humidity (day/night) and $16 / 8 \mathrm{~h}$ of light and darkness for 4 weeks. The $\mathrm{pH}$ of $1 / 2$ Hoagland nutrient solution was standardized at 5.5 and was renewed every 3 days.

The four-week-old seedlings were subjected to $\mathrm{NaCl}$ and drought stress. The seedlings were exposed to $\mathrm{NaCl}$ (0, 50 and $200 \mathrm{mM}$ ) for periods of $0,6,24$, and $48 \mathrm{~h}$, respectively. To affect the water activity for drought stress, the seedlings were exposed to $-0.5 \mathrm{MPa} \mathrm{D}$-sorbitol for $0,6,24$, and $48 \mathrm{~h}$, and the concentration of D-sorbitol was determined according to Lü et al. [50]. The shoots and roots were collected separately and quickly frozen in liquid nitrogen and stored at $-80^{\circ} \mathrm{C}$ for further analysis.

The tissues of the shoots and roots of different $\mathrm{NaCl}$ concentrations $(0,50,100,200,300 \mathrm{mM})$ treated in the period of 0,6 , and $24 \mathrm{~h}$ were collected and mixed together, and the weights were approximately equal. The mixed sample of the different tissues was then prepared for PacBio Iso-seq sequencing. The samples were immediately frozen in liquid nitrogen and stored at $-80^{\circ} \mathrm{C}$ until use.

RNA quantification and quality assessment for sequencing A mirVana miRNA Isolation Kit (Thermo Fisher Scientific, Waltham, MA, USA) was used to extract total RNA. RNA degradation and contamination were assessed on one-percent agarose gels. The NanoDrop 2000 instrument (Thermo Fisher Scientific, Waltham, MA, USA) was used to assess RNA quantity and consistency, and an Agilent 2100 Bioanalyzer (Agilent Technologies, Santa Clara, CA, USA) was used to test RNA integrity.

\section{PacBio Iso-Seq library preparation and sequencing}

The SMRTbell ${ }^{\mathrm{TM}}$ Template Prep Kit 1.0-SPv3 (Pacific Biosciences, Menlo Park, CA, USA) was used to run the sequencing library on $1 \mu \mathrm{g}$ total RNA from the mixed shoot and root sample. The Qubit 2.0 fluorometer (Life Technologies, Carlsbad, CA, USA) was used to check the final library amount and concentration. An Agilent 2100 Bioanalyzer was used to assess library size and purity (Agilent Technologies, Santa Clara, CA, USA). Magbeadloaded SMRTbell template was run on a PacBio Sequel instrument at Shanghai Oe Biotech Co., Ltd. according to Sequel Binding Kit 2.0 instructions (Pacific Bioscience, USA) for primer annealing and polymerase binding (Shanghai, China).

\section{PacBio data analysis}

After Iso-seq quality control (https://github.com/Pacif icBiosciences/IsoSeq SA3nUP/wiki\#datapub), including circular consensus sequence (CCS) generation, classification, and cluster analysis, high-quality consensus isoforms were identified from the original sub-breads. Error correction of the combined high and low quality isoforms 
was performed using RNA-Seq data and LoRDEC software. Using the program TOFU (http://github.com/Pacif icBiosciences/cDNA primer/), high-quality transcripts were generated with an identification value of 0.85 . BLASTX (E-value $\leq 1^{\mathrm{e}-5}$ ) was used to search the nonredundant (NR), SWISS-PROT and Kyoto encyclopedia of genes and genomes (KEGG) [52] protein databases for all known non-redundant transcripts, and putative coding sequences (CDSs) were validated from the highest-ranked proteins. Using BLAST, non-redundant transcripts were aligned with the PlantTFDB (http://plant tfdb.cbi.pku.edu.cn/index.php) and AnimalTFDB (http:// bioinfo.life.hust.edu.cn/AnimalTFDB/) databases to obtain information on transcription factors (TFs).

\section{Identification of the XTH proteins of S. europaea}

To identify the XTH proteins, this study used the current transcriptome sequences from S. europaea, using publicly available datasets from $A$. thaliana, $M$. truncatula and $N$. tabacum $[17,36,53]$ as references. First, 24,869 unigenes from the transcriptome data were searched for all possible S. europaea XTH proteins and the possible XTH protein sequences were additionally identified using Blastp search. The online software SMART (http:// smart.embl-heidelberg.de/) [54] was used to determine conserved domains of putative XTH proteins. HMMER version 3.3.2 was downloaded [55] and used to further validate the predicted protein data with the inclusion of A. thaliana, M. truncatula and $N$. tabacum as a queries; with $\mathrm{E}$ value set to 1e-20. The proteins with XTH domain were conserved for further study.

\section{Phylogenetic analysis, multiple sequence alignment and construction of conserved motifs}

A phylogenetic tree of SeXTH proteins was constructed using MEGA 5.0 with 1000 bootstrap replicates from Maximum Likelihood [56], and AtXTHs from A. thaliana (40), NtXTHs from N. tabacum (50), and MtXTHs from $M$. truncatula (35) were used as queries (Supplementary file 1 ). The A. thaliana and M. truncatula protein sequences were obtained from the Arabidopsis Information Resource (TAIR) database (http://www.arabidopsis. org/) and the NCBI database (https://www.ncbi.nlm.nih. gov/), respectively, and the $N$. tabacum protein sequence was downloaded from Wang et al. [17]. ClustalW was used with default settings to perform multiple sequence alignment of candidate SeXTH proteins at the amino acid level [57]. Furthermore, the conserved motifs in SeXTH proteins were characterized using Multiple Expectation Maximization for Motif Elicitation (MEME) (http:// meme-suite.org/doc/cite.html), examing a motif length of 6-50 sequences and a total of 10 motifs [58].
RNA isolation, cDNA transcription, and RT-qPCR analysis for SeXTH genes

Total RNA was extracted from approximately $100 \mathrm{mg}$ of the frozen shoot and root tissue using the TransZol Up Plus RNA Kit (Lot\#M31018) according to the manufacturer's instructions. RNA quantity and quality were examined using a TGen spectrophotometer (TianGen) based on the A260 nm/A280 nm and A260 nm/A230 $\mathrm{nm}$ ratios. The Evo M-MLV RT Kit (AG11705, Accurate Biotechnology) was used to reverse transcribe total RNA into cDNA and remove genomic DNA mixed in the cDNA, according to the manufacturer's protocol.

RT-qPCR analysis was performed according to MIQE guidelines [59]. Primers were designed based on the mRNA sequences using Primer 5 software (Supplementary file 2) and synthesized by TsingKe Biological Technology Co., Ltd. (Xi'an, China). The Ubiquitin-conjugating $(U B C)$ gene, which is an abiotic stress and tissue universal reference gene in $S$. europaea, was used as a housekeeping/internal control gene [60] and primer pair specificity was determined using RT-qPCR single peak melting curve analysis. Three independent biological replicates were performed and triplicate technical quantitative assays were performed with $0.5 \mu$ l of each cDNA dilution using the Heiff ${ }^{\circledR}$ qPCR SYBR ${ }^{\circledR}$ Green Master Mix kit (Yeasen Biotech Co., Ltd) according to the manufacturer's protocol (Supplementary file 3). The RT-qPCR analysis was performed using the QuantStudio $^{\text {TM }} 5$ Real-Time PCR instrument (ABI). The relative expression of $\mathrm{SeXTH}$ genes was calculated using the $2^{-}$ $\Delta \Delta \mathrm{Ct}$ method [61].

\section{Data analysis}

Gene expression values are presented as means $\pm \mathrm{SD}$ $(n=3)$, and the data were analyzed using SPSS statistical software (Ver. 22.0, SPSS Inc., Chicago, IL, USA) using the one-way ANOVA. At a significance level of $p<0.05$, Duncan's multiple range tests were used to detect differences between means and GraphPad Prism 8 was used to plot all graphs.

\section{Results}

Sequencing and analysis of the transcriptome of $S$. europaea using the PacBio Iso-Seq platform

A higher quality transcriptome assembly was obtained from the mixed samples of the different organs of S. europaea, which was synthesized using the PacBio Iso-Seq system and yielded 16,465,671 subreads. After Iso-Seq quality control, 29,520 isoforms were generated with an average length of $2112 \mathrm{bp}$. A total of 24,869 unigenes were generated with an average length of $2101 \mathrm{bp}$. Using the annotation information, 6398 possible TFs were 
Table 1 The statistics information of 35 SeXTH proteins from S. europaea

\begin{tabular}{|c|c|c|c|}
\hline Name & Transcript ID & Length $(A a)$ & Catalytic Site \\
\hline SeXTH1 & i0_HQ_samplee11669_c1714_f3p2_980 & 278 & DEIDFEFLG \\
\hline $\mathrm{SeXTH} 2$ & i1_HQ_samplee11669_c284462_f3p3_1081 & 262 & DEIDFEFLG \\
\hline SeXTH3 & i1_HQ_samplee11669_c455308_f7p4_1100 & 284 & DEIDFEFLG \\
\hline $\mathrm{SeXTH} 4$ & i0_HQ_samplee11669_c526_f5p0_971 & 269 & DEIDFEFLG \\
\hline SeXTH5 & i1_HQ_samplee11669_c498512_f29p7_1226 & 281 & DEIDFEFLG \\
\hline SeXTH6 & i1_HQ_samplee11669_c456195_f2p5_1122 & 242 & DEIDFEFLG \\
\hline SeXTH7 & i1_HQ_samplee11669_c413025_f29p7_1199 & 283 & DEIDFEFLG \\
\hline SeXTH8 & i1_HQ_samplee11669_c500149_f6p6_1113 & 283 & DEIDFEFLG \\
\hline SeXTH9 & i2_HQ_samplee11669_c21901_f2p2_2292 & 127 & - \\
\hline SeXTH10 & i1_HQ_samplee11669_c9245_f4p1_1355 & 285 & DELDFEFLG \\
\hline SeXTH11 & i1_HQ_samplee11669_c175741_f4p1_1292 & 285 & DELDFEFLG \\
\hline SeXTH12 & i1_HQ_samplee11669_c148489_f3p1_1490 & 338 & DELDFEFLG \\
\hline SeXTH13 & i1_HQ_samplee11669_c33309_f3p1_1216 & 343 & DELDFEFLG \\
\hline SeXTH14 & i1_HQ_samplee11669_c75909_f61p8_1200 & 189 & DEIDFEFLG \\
\hline SeXTH15 & i1_HQ_samplee11669_c175468_f17p8_1201 & 283 & DEIDFEFLG \\
\hline SeXTH16 & i1_HQ_samplee11669_c323900_f11p2_1862 & 384 & DEIDFEFLG \\
\hline SeXTH17 & i1_HQ_samplee11669_c324363_f6p2_1657 & 384 & DEIDFEFLG \\
\hline SeXTH18 & i1_HQ_samplee11669_c456730_f3p0_126 & 292 & NEFDFEFLG \\
\hline SeXTH19 & i1_HQ_samplee11669_c413221_f5p0_1297 & 290 & NEFDFEFLG \\
\hline SeXTH2O & i1_HQ_samplee11669_c456125_f4p5_1076 & 269 & DEIDFEFLG \\
\hline SeXTH21 & i3_HQ_samplee11669_c15535_f2p3_3018 & 269 & DEIDFEFLG \\
\hline $\mathrm{SeXTH} 22$ & i1_HQ_samplee11669_c6078_f5p0_1381 & 342 & DELDIEFLG \\
\hline $\mathrm{SeXTH} 23$ & i1_HQ_samplee11669_c500266_f6p1_1044 & 282 & DEIDFEFLG \\
\hline $\mathrm{SeXTH} 24$ & i1_HQ_samplee11669_c501908_f3p1_1100 & 284 & DEIDFEFLG \\
\hline $\mathrm{SeXTH} 25$ & i1_HQ_samplee11669_c119883_f27p1_1259 & 296 & DEIDMEFLG \\
\hline SeXTH26 & i0_HQ_samplee11669_c858_f7p2_997 & 159 & DEIDFEFLG \\
\hline SeXTH27 & i1_HQ_samplee11669_c243646_f13p5_1193 & 159 & DEIDFEFLG \\
\hline $\mathrm{SeXTH} 28$ & i1_HQ_samplee11669_c45533_f5p5_1441 & 236 & DEVDFEFLG \\
\hline SeXTH29 & i1_HQ_samplee11669_c498_f39p5_1467 & 289 & DEVDFEFLG \\
\hline SeXTH30 & i1_HQ_samplee11669_c322708_f7p5_1222 & 216 & DEIDFEFLG \\
\hline SeXTH31 & i1_HQ_samplee11669_c499858_f10p6_1142 & 247 & DEIDFEFLG \\
\hline SeXTH32 & i1_HQ_samplee11669_c9096_f2p5_1303 & 176 & - \\
\hline SeXTH33 & i1_HQ_samplee11669_c134347_f3p1_1137 & 144 & DEIDFEFLG \\
\hline SeXTH34 & i1_HQ_samplee11669_c581117_f2p1_1026 & 144 & DEIDFEFLG \\
\hline SeXTH35 & i1_HQ_samplee11669_c414106_f24p2_1215 & 149 & DEIDFEFLG \\
\hline
\end{tabular}

predicted. The unigenes were used to predict the coding region sequences after BLASTX search. The results yielded 24,414 unigenes predicted by CDS (98\% of the total unigenes) and a total of 182 interspersed repeats with a total length of $10,989 \mathrm{bp}$. The raw sequence data were submitted to the NCBI Sequence Read Achieve database with accession number: PRJNA725943 (https:// submit.ncbi.nlm.nih.gov/subs/sra).

\section{Identification of S. europaea XTH proteins}

Generally, members of XTH family are conserved in various species. Therefore, 24,869 unigenes were searched from the transcriptome data of $S$. europaea for all possible SeXTH proteins, and 35 best non-redundant potential candidates were obtained and confirmed by BLAST on NCBI database (Supplementary file 4) and the HMMER version 3.3.2 software (Supplementary file 5). They were renamed from SeXTH1 to SeXTH35, respectively. It was discovered that SeXTH4/5, SeXTH7/8, SeXTH10/11, SeXTH26/27 and SeXTH33/34 were different transcripts of the same genes. The predicted length of the $35 \mathrm{SeXTH}$ proteins revealed that SeXTH16 and -17 had the longest protein sequence with 384 amino acids, and the smallest was SeXTH9 with 127 amino acids (Table 1). 


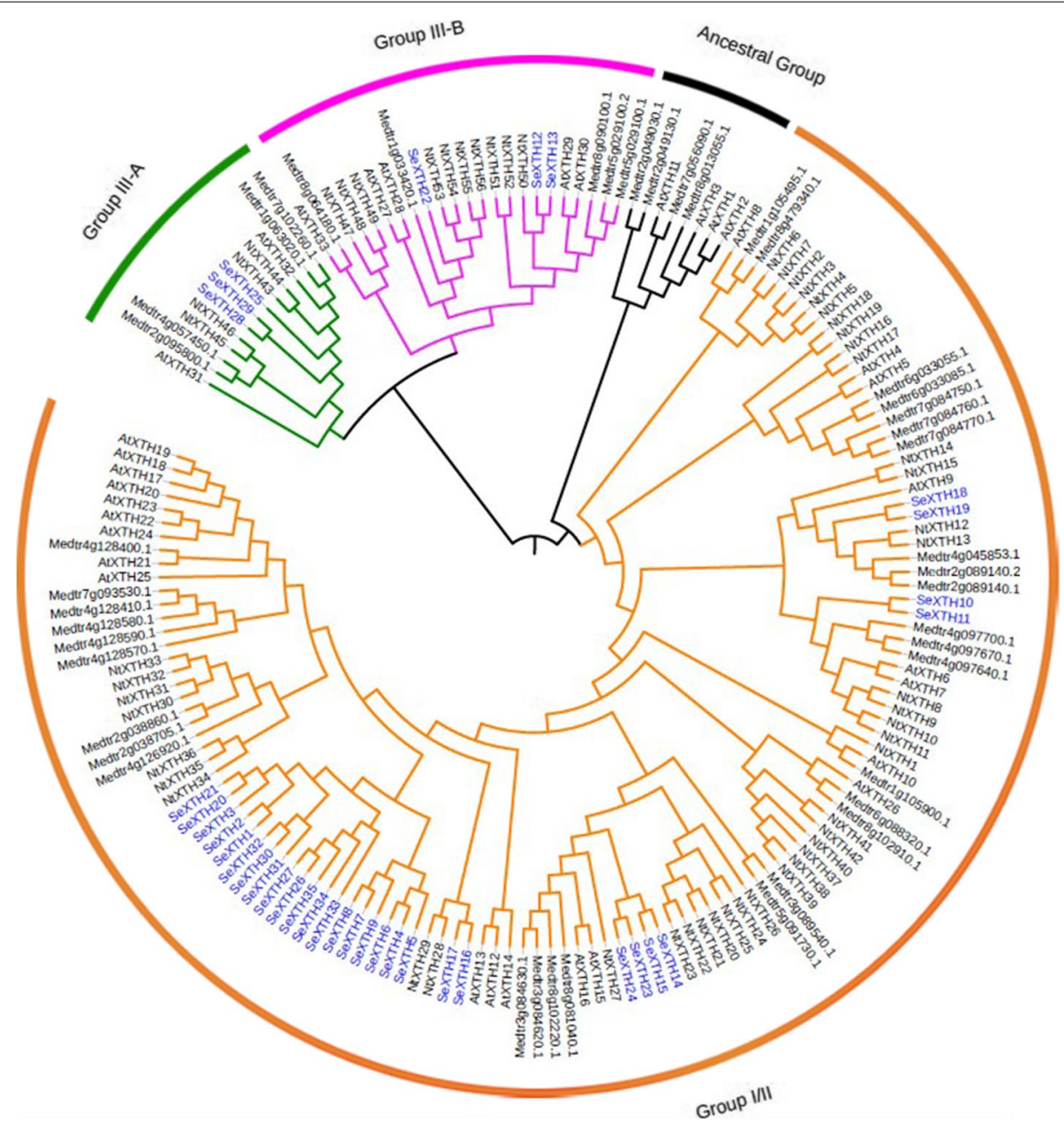

Fig. 1 Phylogenetic tree of the proteins of S. europaea, A. thaliana, M. truncatula and N. tabacum. The different colored branches and arcs show Group I/II, IIIA, IIIB and Ancestral Group, respectively, with SeXTH members highlighted in blue. SeXTHs represent XTH members from S. europaea, AtXTHs represent $A$. thaliana members and M. truncatula members represent MedtrxxXX

\section{Phylogenetic analysis of SeXTH proteins}

Phylogenetic analysis of plant XTH proteins is a reliable way to understand the functions of unknown XTH members based on their genetic history and sequence consistency. Therefore, all thirty-five (35) SeXTH proteins identified with ExDxE domains were used to construct the phylogenetic relationship tree. The SeXTH proteins were clustered into group I/II, IIIA and IIIB. The majority of the proteins clustered into group I/II, which included twenty-nine (29) members. Similarly, group III consisted of SeXTH12, $-13,-22,-25,-28$, and -29 and was further subdivided into group IIIA and group IIIB as defined previously $[62,63]$. In S. europaea, no XTH protein was detected in the ancestral group (Fig. 1).

\section{Multiple sequence alignment of SeXTH proteins}

The active site (ExDxE), which represents the catalytically active residues, was highly conserved in SeXTH proteins. In our study, the conserved domain $\mathrm{DE}(\mathrm{I} / \mathrm{L} /$ F/V)D(F/I/M)EFLG was identified in all SeXTH proteins except SeXTH9 and-32, which were, however, confirmed to be members of the glycoside hydrolase 16 family by HMMER analysis. A potential N-linked glycosylation site sharing $\mathrm{N}(\mathrm{T}) \mathrm{V}(\mathrm{R} / \mathrm{L} / \mathrm{T} / \mathrm{I}) \mathrm{T}(\mathrm{S} / \mathrm{K} / \mathrm{R} / \mathrm{F} / \mathrm{P}) \mathrm{G}$ is located near the catalytic residues in $33 \mathrm{SeXTH}$ proteins (Table 1, Fig. 2).

\section{Analysis of conserved motifs in SeXTH proteins}

We examined the diversity of motifs in the regions of SeXTH proteins using the MEME database (http:// meme.nbcr.net/meme/). Ten (10) types of motifs from $S$. europaea were identified. Analysis revealed that motif 1 contained the conserved ExDxE active site. Importantly, 


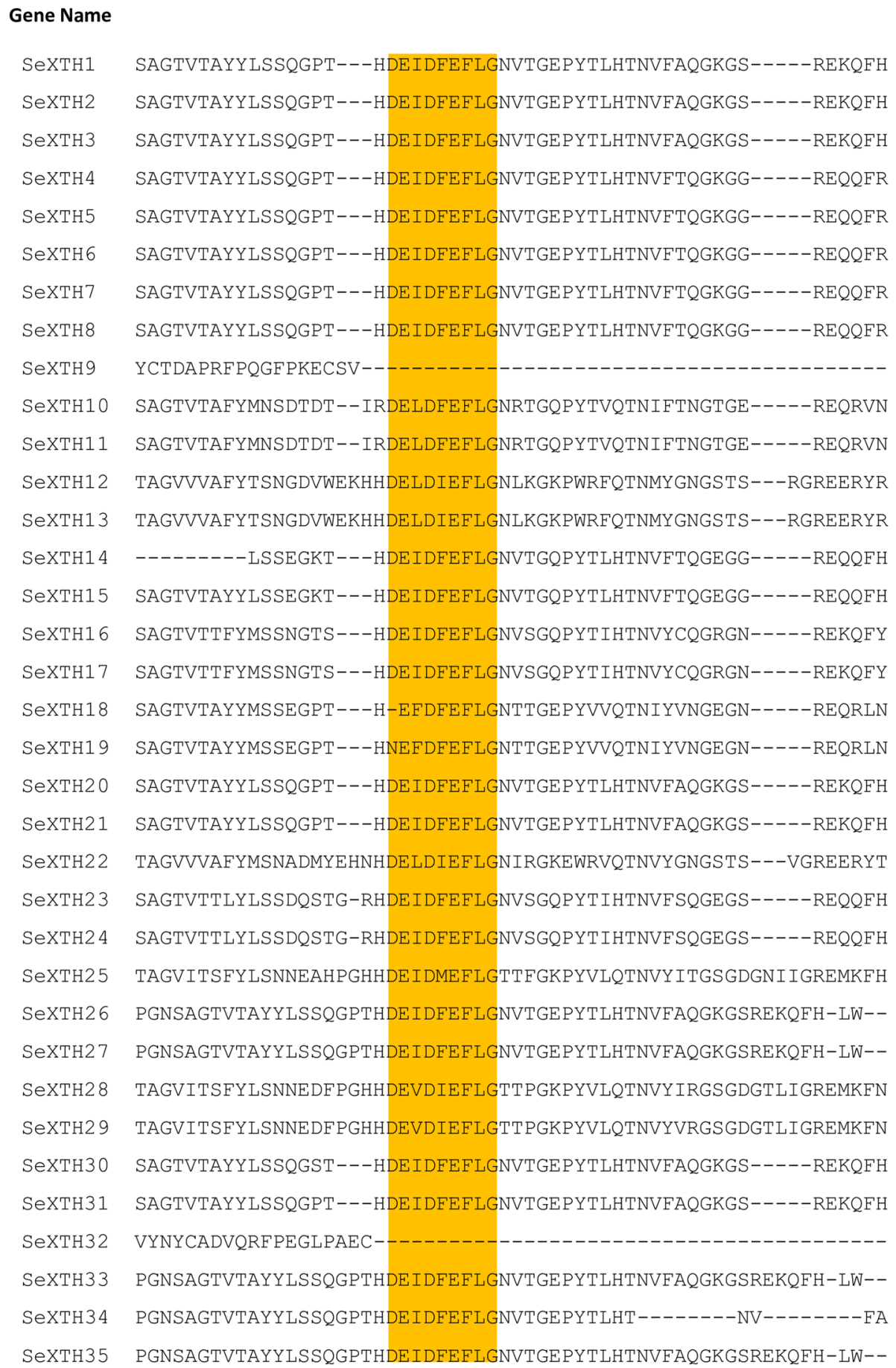

Fig. 2 Multiple sequence alignment of the 35 SeXTH proteins. Missing amino acids are represented by dashes, while conserved XTH domains are highlighted in gold

motif 3 had the highest amino acid sequences, while motif 8 contained the fewest amino acid sequences. The majority of SeXTH proteins contained most of the motifs. For example, $11 \mathrm{SeXTH}$ proteins contained 9 types of motifs and $8 \mathrm{SeXTH}$ proteins contained 8 types of motifs. Five SeXTH proteins had 6 types of motifs, four SeXTH proteins contained 7 and 4 types of motifs, respectively, two SeXTH proteins had 5 types of motifs, 


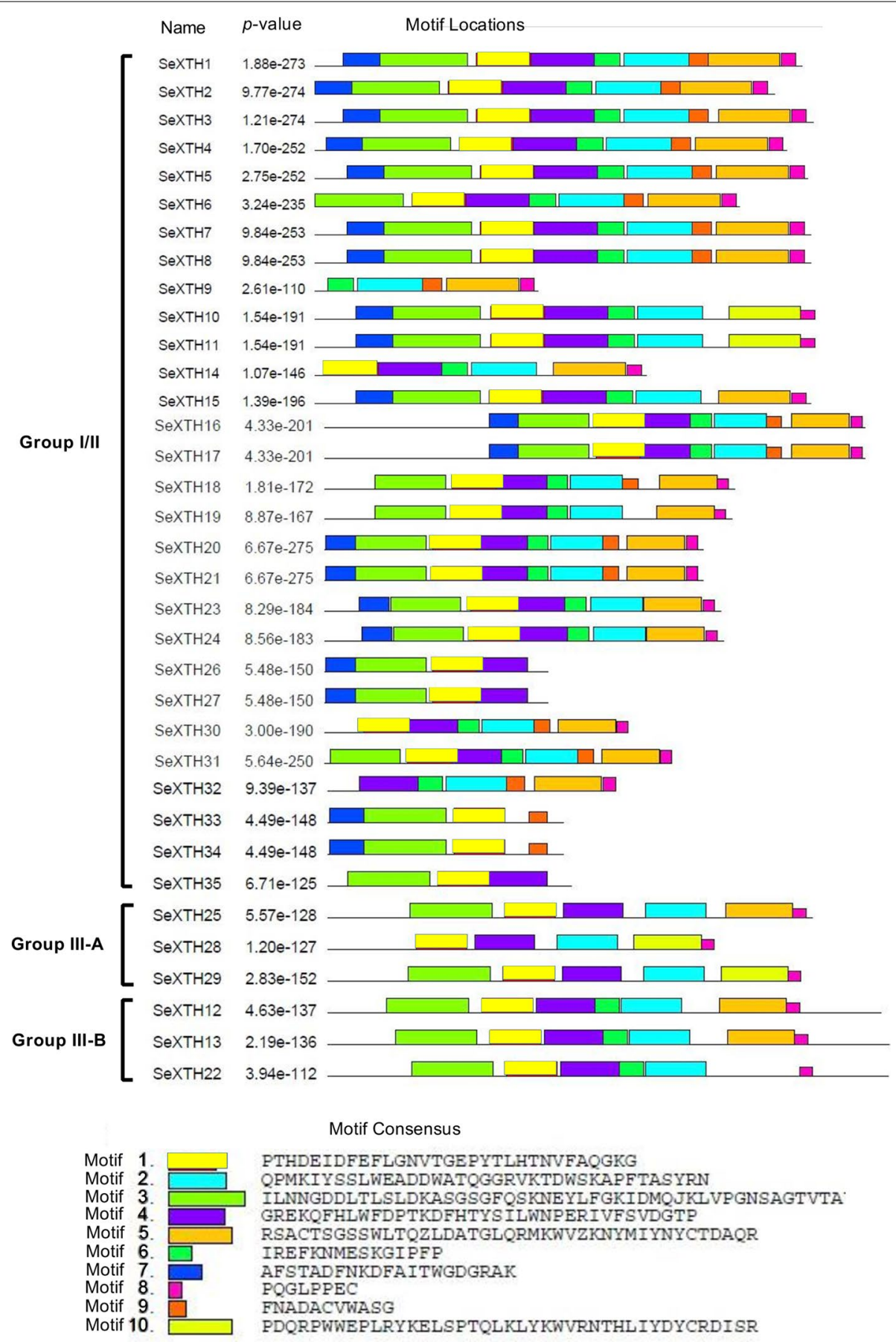

Fig. 3 Conserved XTH protein motifs in S. europaea. The motif composition of the SeXTH protein was identified using MEME. The different colored boxes represent different motifs and their position in each SeXTH sequence. Each motif is indicated by a colored box in the legend at the bottom

and only 1 SeXTH had 3 types of motifs. Motifs 7 and -9 were present only in group I/II. The different types of motifs exhibited by the SeXTH proteins were not defined (Fig. 3).

\section{Expression pattern of SeXTH genes in response to $\mathrm{NaCl}$ stress by RT-qPCR}

To investigate the relative expression pattern of SeXTHs in response to different abiotic stress conditions, the expression patterns of the $35 \mathrm{SeXTHs}$ in response to 
salinity were examined and shown in Fig. 4. This analysis revealed that some members of the $\mathrm{SeXTH}$ genes have distinct tissue-specific expression profiles. For example, within group I/II, SeXTH10/11 was mainly expressed in roots and SeXTH17 in shoots. In addition, individual $\mathrm{SeXTH}$ genes responded differently to $\mathrm{NaCl}$ stress and time: $24 \mathrm{~h}$ recorded the highest number of members (15 $\mathrm{SeXTHs)}$ significantly expressed in all treatments and tissues, with an average fold-change of 5.7 compared to control. Under 0,50 , and $200 \mathrm{mM} \mathrm{NaCl}, 27$ and 15 $\mathrm{SeXTHs}$ were expressed in shoots and roots respectively, after 24h (Fig. 4).

\section{Expression pattern of SeXTH genes in response to drought stress by RT-qPCR}

Under drought, $21 \mathrm{SeXTHs}$ showed statistically significant expression patterns in roots after $48 \mathrm{~h}$ of drought stress with $2.6,1.4,2.6,4.5,1.6,4.4,2.3,0.7,0.3,2.4,2.1$, $1.4,2.2,1.4,1.5,1.8,3.5,2.0,1.7,10.4,3.4$ times higher compared to control. The expression levels of SeXTH16, $-22,-28,-33 / 34$ and -35 were highly increased in roots after $24 \mathrm{~h}$. In shoots, $13 \mathrm{SeXTHs}$ were up-regulated and the expression levels of $\mathrm{SeXTH} 4 / 5,-7 / 8,-9,-31$ and -32 were down-regulated at the onset of drought stress and then increased after $48 \mathrm{~h}$. SeXTH16, -23 , $-28,-33 / 34$, and -35 were also significantly increased after $24 \mathrm{~h}$ with fold-change of $7.9,8.8,1.2,10.6$, and 12.1, respectively compared to the control. The remaining genes showed different expression patterns in both roots and shoots depending on the duration of drought (Fig. 5).

\section{Discussion}

Several non-model plants that thrive in harsh environments have evolved specialised mechanisms to survive that are of great value to scientific research. In species without a published genome or with an incomplete sequenced genome, such as S. europaea, the phenomenon of PacBio Iso-Seq transcriptome sequencing facilitates the study of transcriptomes and the expression profiling of relevant genes [24, 47]. In the present study, 24,869 high-quality unigenes were generated by PacBio sequencing and 24,414 unigenes were predicted using CDSs (98\% of the total unigenes). Using the annotation information, 6398 possible TFs were predicted while another study on S. europaea discovered 171 and 143 transcription factors among DEGs in roots and shoots, respectively [24]. In walnut (Juglans regia), Sadat-Hasseini et al. [47] reported 3931 TFs when transcripts were searched using BLAST search. The unigene and annotation data in this study had higher quality. This suggests that the unigene data are of higher quality and suitable for gene identification, characterization and expression analysis. To the best of our knowledge, only three studies have investigated transcriptome profiling of S. europaea. These three previous studies had used the Illumina sequencing technique for transcriptome profiling, and although they generated the largest number of unigenes, this study used PacBio Iso-Seq to capture the most coding sequence unigenes and also the longest length unigenes $[16,24,48]$. In addition, none of the studies made use of interspersed repeats, which account for $25-40 \%$ of the genomes of most higher organisms and allow genetic mutations to arise [64]. Based on these analogies, we are confident that the transcriptome data from PacBio IsoSeq are more reliable in S. europaea. However, we suggest that further studies should be conducted in other organisms.

Global identification of $X T H$ genes will help to understand gene expression and regulatory mechanisms for plant tolerance to environmental stresses such as salinity and drought. To date, many XTH genes have been identified in plants, including 33 in A. thaliana [39], 29 in O. sativa [37], 25 genes in S. lycopersicum [43], 56 in $N$. tabacum [17], 61 in G. $\max$ [36] and H. vulgare [38]. In this study, $35 X T H$ genes encoding the XTH domain were detected from $S$. europaea. In comparison, the number of $\mathrm{SeXTH}$ genes identified was slightly higher than that of A. thaliana (33), O. sativa (29), S. lycopersicum (25), and $H$. vulgare (24), suggesting that this might be a result of gene gains and losses [35]. SeXTH genes were categorized into three clusters: 29 genes formed group I/II, 3 were classified into group IIIA, and also 3 were classified into group IIIB, as described previously [62]. Previous studies reported that there was no significant divergence between group I and group II, which formed the largest cluster and is referred to as group I/II [38, 39]. So, this might be the reason that group I and group II were clustered together in this study (Fig. 1) and also had the largest members. Although group IIIB had obvious XET activity, group IIIA had significant XEH activity [26, 63], confirming a functional distinction between subgroup IIIA and IIIB. Therefore, we speculated that SeXTH12, -13 , and -22 in group IIIB might possess XET activities and $\mathrm{SeXTH} 25,-28$, and -29 in group IIIA might exert $\mathrm{XEH}$ activity in S. europaea under abiotic stress. Further studies are required to fully elucidate the absence of an ancestral group in the $X T H$ gene family of S. europaea.

XTH proteins have been found to have several conserved modular structures, including a short hydrophobic amino region that likely serves as a signal peptide to direct the protein to the plant cell wall and a highly conserved DEIDFEFLG domain that serves as a catalytic site for both XET and XEH activity [65]. In this study, a highly conserved XTH domain DEIDFEFLG was detected in almost all SeXTHs and an N-linked 

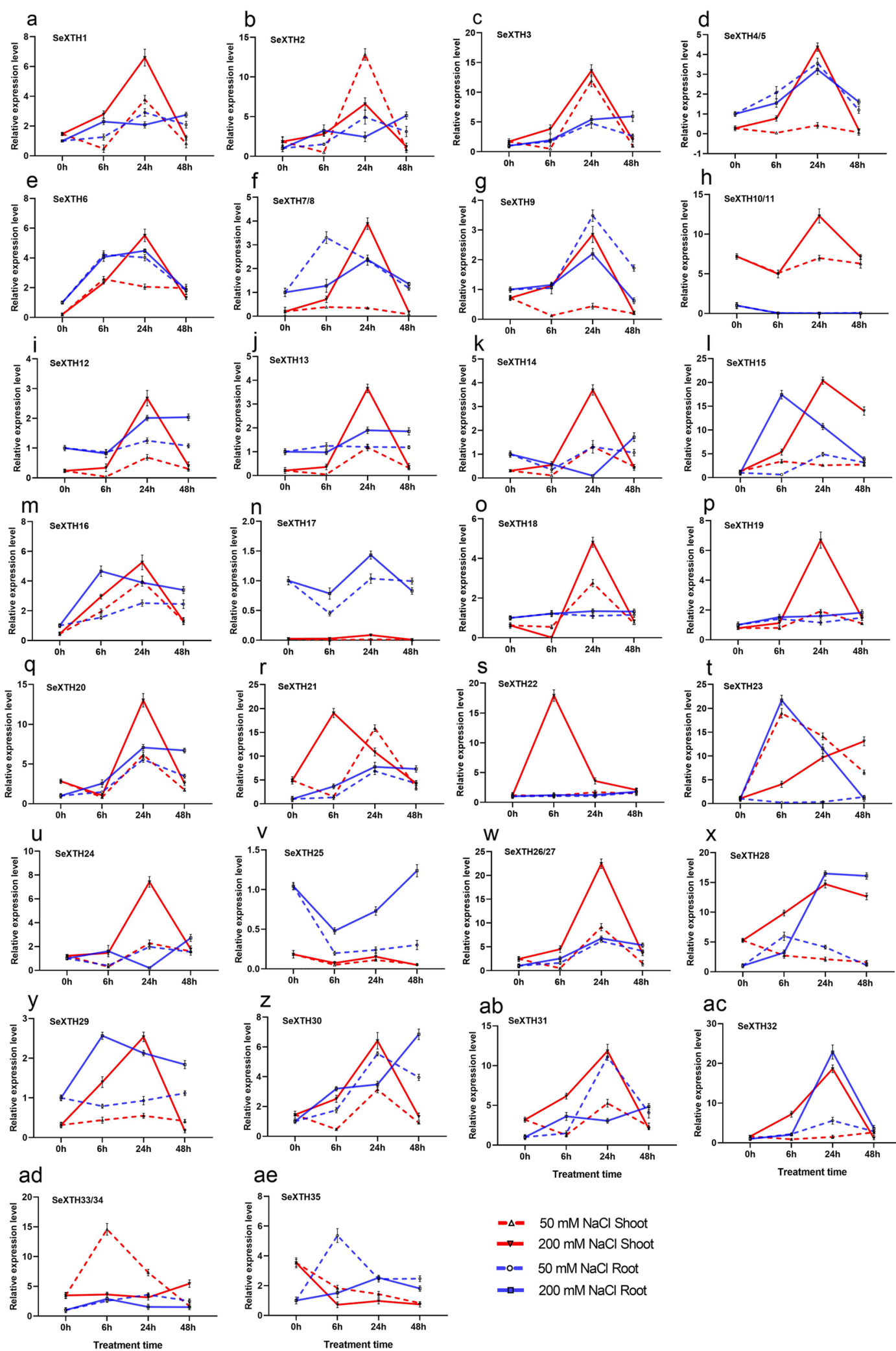

ae
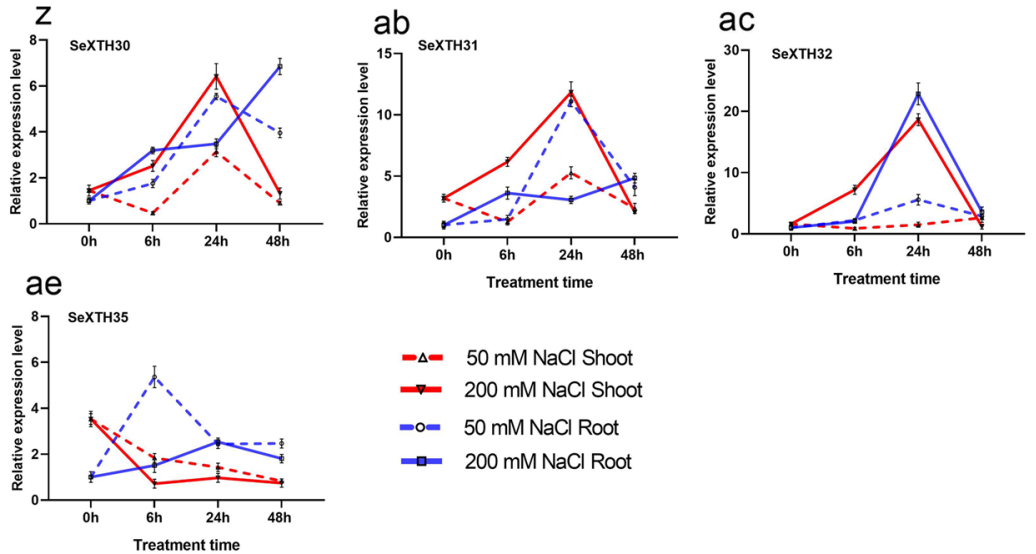

Fig. 4 RT-qPCR analysis of the expression of $35 \mathrm{SeXTH}$ genes in response to $\mathrm{NaCl}$ stress. The red and blue dashed lines represent $50 \mathrm{mM} \mathrm{NaCl}$ for shoot and root; the continued red and blue lines indicate $200 \mathrm{mM} \mathrm{NaCl}$ for shoot and root. The name of the gene is indicated at the top left top of each line graph 

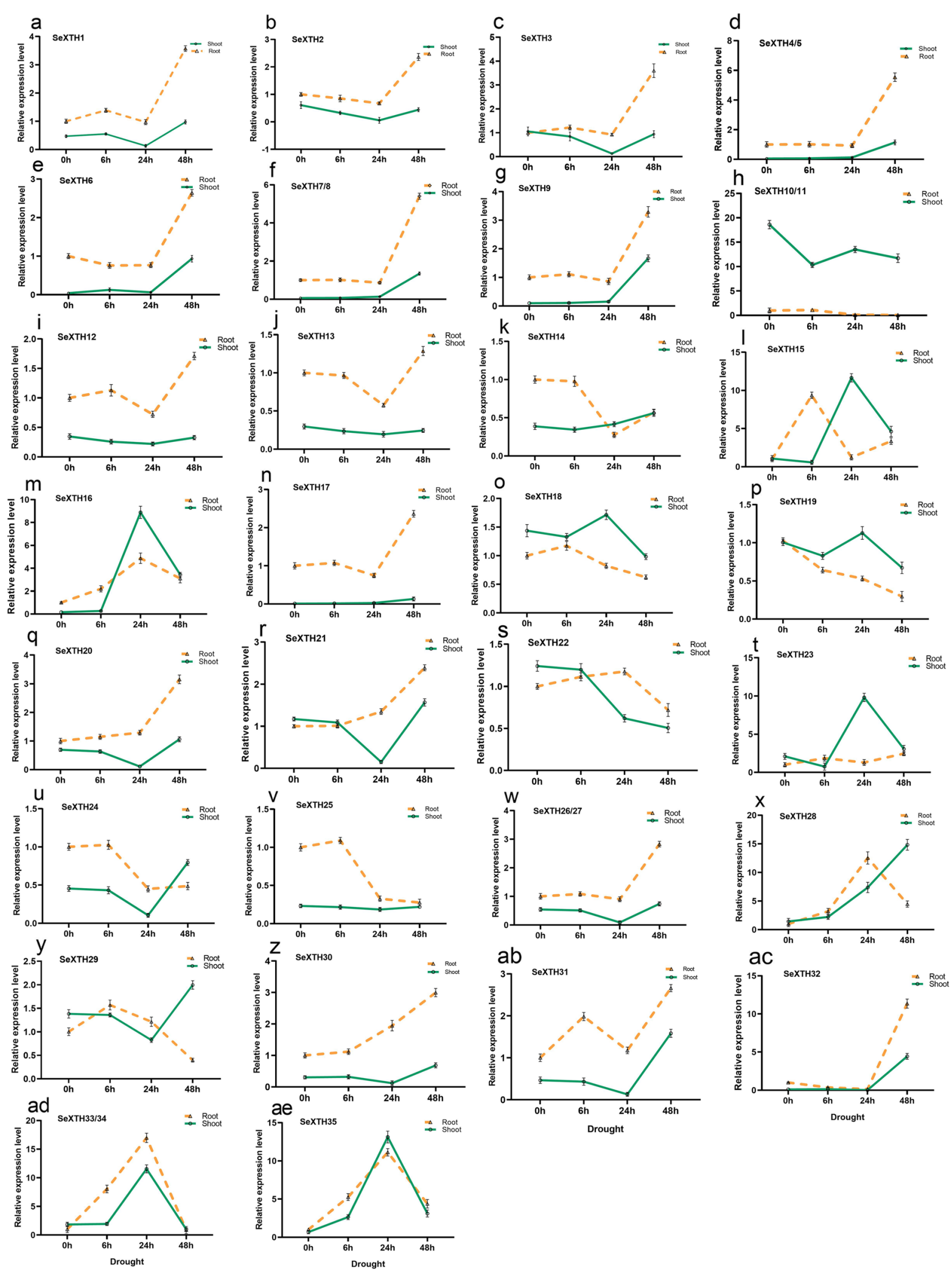

Fig. 5 RT-qPCR analysis of the expression of 35 SeXTH genes in response to drought stress. The dashed lines represent roots and the continuous lines indicate shoots. The name of the gene is indicated at the top left of each line graph 
glycosylation site $\mathrm{N}(\mathrm{T}) \mathrm{V}(\mathrm{R} / \mathrm{L} / \mathrm{T} / \mathrm{I}) \mathrm{T}(\mathrm{S} / \mathrm{K} / \mathrm{R} / \mathrm{F} / \mathrm{P}) \mathrm{G}$ was discovered near the catalytic residues (Fig. 2). However, it was discovered that the third amino acid, isoleucine (I), can also be replaced by alternative hydrophobic residues; either leucine $(\mathrm{L})$, phenylalanine $(\mathrm{F})$ or valine $(\mathrm{V})$, and finally the fifth amino acid phenylalanine (F) can be replaced by isoleucine (I). This phenomenon has also been reported when comparing some catalytic domains of Arabidopsis XTHs [39, 65]. In this study, we discovered that the fifth phenylalanine (F) residue of SeXTH25 was replaced by methionine (M). Since the apolar and uncharged structure of the residues is preserved, Fu et al. [38] anticipated that these modifications would have little effect on the cleavage of the xyloglucanglycan chain bonds. Interestingly, all ten (10) different types of motifs were conserved in S. europaea. Although the functions of the SeXTH motifs remain unclear, it is quite convincing that all the different motifs present in the SeXTH protein suggest that they might have different biochemical and biological functions under environmental stress.

Molecular control mechanisms for abiotic stress tolerance rely on the activation and regulation of specific stress-related genes. These genes are involved in the entire sequence of stress responses such as signal transduction, transcriptional control, membrane and protein protection [2]. The expression of XTHs varies upon stress exposure and exhibits tissue, organ, and time specificity [66]. In this study, the pattern of SeXTHs showed differential expression under different tissues, time, and $\mathrm{NaCl}$ treatments. For example, SeXTH10/11 within group I/II was mainly expressed in roots but not in other tissues. The same phenomenon was reported in $O$. sativa, where seven $X T H$ genes $(O s X T H 1,-2$, $-4,-13,-15,-16$, and -25$)$ were expressed mainly in roots of 14-day-old seedlings, whiles no expression was detected in other tissues [37]. SeXTH17 was also found to be significantly expressed in shoots. A similar phenomenon was reported by Rose et al. [28], where AtXTH24 was strongly expressed in shoots of A. thaliana. When the plantlets were exposed to 0,50 , and $200 \mathrm{mM} \mathrm{NaCl}, 27$ and $15 \mathrm{SeXTH}$ genes were highly expressed in shoots and roots, respectively, after $24 \mathrm{~h}$ at $200 \mathrm{mM} \mathrm{NaCl}$. Similarly, MtXTH3 gene was significantly up-regulated in the shoots and roots of M. truncatula when $\mathrm{NaCl}$ stress exceeded $150 \mathrm{mM} \mathrm{NaCl}$; CaXTH3 was also shown to increase salt tolerance in transgenic $A$. thaliana plants $[35,43]$. Thus, these results suggest that several SeXTH genes are involved in high salt resistance that is tissue specific and functional redundancy based on expression patterns may not exist.
To better understand the possible function of $\mathrm{SeXTH}$ genes under drought stress, we also analyzed in detail the expression of $X T H$ genes in S. europaea. A previous study reported that the expression of the CaXTH3 gene from $C$. annuum was up-regulated when seedlings were exposed to extreme drought to improve drought resistance in transgenic A. thaliana [40] and S. lycopersicum [43]. In this work, rigorous expression analysis also showed that under $48 \mathrm{~h}$ of drought, 21 and 13 $\mathrm{SeXTH}$ genes were up-regulated in roots and shoots, respectively. Therefore, it would be reasonable to assume that the $34 \mathrm{SeXTH}$ genes in S. europaea could be functional during the adaptation process to abiotic stress responses. In shoots, $\mathrm{SeXTH4/5},-7 / 8,-9,-31$, and -32 were down-regulated at the onset of drought stress, which is consistent with the expression of several XTH isoform genes (AtXTH6, - 9, - 15, and - 16) in Arabidopsis during mild and severe drought stress [66]. Also, Wu et al. [67] reported that XTH activity was reduced in the elongation region of soybean seedlings under low water potential. There were different expression patterns in both roots and shoots depending on the duration of drought stress. According to Tenhaken [68], different expression patterns of $X T H$ genes were also found in shoots and roots of Arabidopsis plants subjected to $24 \mathrm{~h}$ drought stress. All the reported results clearly indicate that the expression of $\mathrm{SeXTH}$ genes can be an effective tool to improve the stress tolerance of some plants.

\section{Conclusion}

In this study, 24,869 high-quality unigenes were generated by PacBio sequencing and $98 \%$ of these unigenes were predicted by CDSs. Based on this study, the transcriptome data from PacBio sequencing are more reliable in S. europaea. In this current study, $35 \mathrm{SeXTH}$ proteins from $S$. europaea were discovered using bioinformatics. Based on their sequence conservation, the SeXTH proteins could be classified into three groups: Group I/II, Group IIIA and IIB according to their phylogenetic relationship. All showed the conserved domain $\mathrm{DE}(\mathrm{I} / \mathrm{L} / \mathrm{F} / \mathrm{V})$ DF(I/M)EFLG with a potential N-linked glycosylation domain $\mathrm{N}(\mathrm{T}) \mathrm{V}(\mathrm{R} / \mathrm{L} / \mathrm{T} / \mathrm{I}) \mathrm{T}(\mathrm{S} / \mathrm{K} / \mathrm{R} / \mathrm{F} / \mathrm{P}) \mathrm{G}$. Expression analysis confirmed that $\mathrm{SeXTH}$ genes can help plants resist environmental stress.

\section{Abbreviations}

XTH: Xyloglucan endotransglycosylase/hydrolase; GH16: Glycoside hydrolase 16; GH16-XET: GH16 domain of XET; C-XET: C-terminal domain of XET; XEH: Xyloglucan endo-hydrolase; XET: Xyloglucan endo-transglycosylase; RNASeq: RNA sequencing; Iso-Seq: Isoform sequencing; CCS: Circular consensus 
sequences; CDSs: Coding sequences; NR: Non-redundant; KEGG: Kyoto Encyclopedia of Genes and Genomes; TFs: Transcription factors; MEME: Multiple expectation maximization for motif elicitation; RT-qPCR: Real-time quantitative polymerase chain reaction; UBC: Ubiquitin-conjugating; SRA: Sequence read archive.

\section{Supplementary Information}

The online version contains supplementary material available at https://doi. org/10.1186/s12870-021-03269-y.

Additional file 1: Supplementary file 1. XTH sequences from A. thaliana, N. tabacum and M. truncatula used for phylogenetic tree construction.

Additional file 2: Supplementary file 2. The primer sequences used for the RT-qPCR analysis.

Additional file 3: Supplementary file 3. The RT-qPCR raw data.

Additional file 4: Supplementary file 4. Amino acid sequence of the predicted $35 \mathrm{SeXTH}$ proteins.

Additional file 5: Supplementary file 5. The HMMER validation of the number of SeXTH genes present in S. europaea.

\section{Acknowledgements}

Not applicable.

\section{Authors' contributions}

R. J.T and H. R. D. designed the experiment. J.W. and G. X. C. performed the experiments. R. J.T., H. R. D. and J. W. analyzed transcriptome data. R. J. T and H. R. D. wrote the paper. G. X. C., J. Y. M. and H. S. Y. revised this paper. All authors have read and approved the manuscript.

\section{Funding}

This research was funded by the Natural Science Foundation of China (31700338), the Natural Science Foundation of Gansu Province (20JR5RA578), the Science and Technology Innovation Program of Lanzhou Institute of Husbandry and Pharmaceutical Science, Chinese Academy of Agricultural Sciences (CAAS-LMY-04), the Innovation Project of Chinese Academy of Agricultural Sciences (CAAS-XTCX2016011-02) and the Gansu Provincial Science and Technology Major Projects (19ZD2NA002).

\section{Availability of data and materials}

All raw sequence data have been submitted to the Sequence Read Archive (SRA) database under accession number PRJNA725943 (https://submit.ncbi. nlm.nih.gov/subs/sra).

\section{Declarations}

Ethics approval and consent to participate

Not applicable.

\section{Consent for publication}

Not applicable.

\section{Competing interests}

The authors declare that they have no competing interests.

\section{Author details}

${ }^{1}$ Lanzhou Institute of Husbandry and Pharmaceutical Science, Chinese Academy of Agricultural Sciences, Lanzhou, China. ${ }^{2}$ College of Forestry, Gansu Agricultural University, Lanzhou, China.

Received: 16 May 2021 Accepted: 11 October 2021

Published online: 25 October 2021

\section{References}

1. Lotfi N, Soleimani A, Vahdati K, Çakmakçı R. Comprehensive biochemical insights into the seed germination of walnut under drought stress. Sci Hortic. 2019;250:329-43.

2. Vahdati K, Lotfi N. Abiotic stress tolerance in plants with emphasizing on drought and salinity stresses in walnut. In: Vahdati K, Leslie C, editors. Abiotic stress-plant responses and applications in agriculture. Rijeka: InTech; 2013. p. 307-65.

3. Lv S, Jiang $\mathrm{P}$, Chen $\mathrm{X}$, Fan $\mathrm{P}$, Wang $\mathrm{X}$, Li Y. Multiple compartmentalization of sodium conferred salt tolerance in Salicornia europaea. Plant Physiol Biochem. 2012;51:47-52.

4. Lv S, Nie L, Fan P, Wang X, Jiang D, Chen X, et al. Sodium plays a more important role than potassium and chloride in growth of Salicornia europaea. Acta Physiol Plant. 2012;34(2):503-13.

5. Lotfi N, Vahdati K, Kholdebarin B, Hassani D, Amiri R. Peroxidase, guaiacol peroxidase and ascorbate peroxidase activity accumulation in leaves and roots of walnut trees in response to drought stress. Acta Hortic. 2010;861:309-16.

6. Liska AJ, Shevchenko A, Pick U, Katz A. Enhanced photosynthesis and redox energy production contribute to salinity tolerance in Dunaliella as revealed by homology-based proteomics. Plant Physiol. 2004;136(1):2806-17.

7. Lotfi N, Vahdati K, Kholdebarin B, Amiri R. Soluble sugars and proline accumulation play a role as effective indices for drought tolerance screening in Persian walnut (Juglans regia L.) during germination. Fruits. 2010;65(2):97-112.

8. Mazel A, Leshem Y, Tiwari BS, Levine A. Induction of salt and osmotic stress tolerance by overexpression of an intracellular vesicle trafficking protein AtRab7 (AtRabG3e). Plant Physiol. 2004;134(1):118-28.

9. Zhu JK. Salt and drought stress signal transduction in plants. Annu Rev Plant Biol. 2002;53:247-73.

10. Barkla BJ, Pantoja O. Plasma Membrane and Abiotic Stress. In: Murphy AS, Schulz B, Peer W, editors. The Plant Plasma Membrane. Berlin, Heidelberg: Springer Berlin Heidelberg; 2011. p. 457-70.

11. Rezaei Qusheh Bolagh F, Solouki A, Tohidfar M, Zare Mehrjerdi M, IzadiDarbandi A, Vahdati K. Agrobacterium-mediated transformation of Persian walnut using $B A D H$ gene for salt and drought tolerance. J Horticultural Sci Biotechnol. 2020;95(4):1-10.

12. Shi H, Ishitani M, Kim C, Zhu J-K. The Arabidopsis thaliana salt tolerance gene SOS1 encodes a putative $\mathrm{Na}^{+} / \mathrm{H}^{+}$antiporter. Proc Natl Acad Sci U S A. 2000;97(12):6896-901.

13. Ardie SW, Xie L, Takahashi R, Liu S, Takano T. Cloning of a high-affinity $\mathrm{K}^{+}$ transporter gene PUtHKT2;1 from Puccinellia tenuiflora and its functional comparison with OsHKT2;1 from rice in yeast and Arabidopsis. J Exp Bot. 2009;60(12):3491-502.

14. Rus A, Yokoi S, Sharkhuu A, Reddy M, Lee B-H, Matsumoto TK, et al. AtHKT is a salt tolerance determinant that controls $\mathrm{Na}^{+}$entry into plant roots. Proc Natl Acad Sci U S A. 2001;98(24):14150-5.

15. Berthomieu P, Conéjéro G, Nublat A, Brackenbury WJ, Lambert C, Savio C, et al. Functional analysis of AtHKT1 in Arabidopsis shows that $\mathrm{Na}^{+}$recirculation by the phloem is crucial for salt tolerance. EMBO J. 2003:22(9):2004-14

16. Ma J, Zhang M, Xiao X, You J, Wang J, Wang T, et al. Global transcriptome profiling of Salicornia europaea L. shoots under $\mathrm{NaCl}$ treatment. PLoS One. 2013;8(6):e65877.

17. Wang $M, X u Z$, Ding A, Kong Y. Genome-Wide Identification and Expression Profiling Analysis of the Xyloglucan Endotransglucosylase/Hydrolase Gene Family in Tobacco (Nicotiana tabacum L.). Genes. 2018;9(6):273.

18. Nikalje GC, Srivastava AK, Pandey GK, Suprasanna P. Halophytes in biosaline agriculture: mechanism, utilization, and value addition. Land Degradation Dev. 2018;29(4):1081-95.

19. Davy AJ, Bishop GF, Costa CSB. Salicornia L.(Salicornia pusilla J. woods, S. ramosissima J. woods, S. europaea L., S. obscura PW ball \& Tutin, S. nitens PW ball \& Tutin, S. fragilis PW ball \& Tutin and S. dolichostachya Moss). J Ecol. 2001;89(4):681-707.

20. Flowers TJ, Colmer TD. Salinity tolerance in halophytes. New Phytol. 2008:179(4):945-63.

21. Ozawa T, Wu J, Fujii S. Effect of inoculation with a strain of pseudomonas pseudoalcaligenes isolated from the endorhizosphere of Salicornia europea on salt tolerance of the glasswort. Soil Sci Plant Nutr. 2007;53(1):12-6.

22. Ventura Y, Wuddineh WA, Myrzabayeva M, Alikulov Z, Khozin-Goldberg I, Shpigel M, et al. Effect of seawater concentration on the productivity and nutritional value of annual Salicornia and perennial Sarcocornia halophytes as leafy vegetable crops. Sci Hortic. 2011;128(3):189-96. 
23. Aslamsup R, Bostansup N, Mariasup M, Safdar W. A critical review on halophytes: salt tolerant plants. J Med Plants Res. 2011;5(33):7108-18.

24. Fan $P$, Nie $L$, Jiang $P$, Feng J, Lv $S$, Chen $X$, et al. Transcriptome analysis of Salicornia europaea under saline conditions revealed the adaptive primary metabolic pathways as early events to facilitate salt adaptation. PLoS One. 2013;8(11):e80595.

25. Panta S, Flowers T, Lane P, Doyle R, Haros G, Shabala SJE. Halophyte agriculture: success stories. Environ Exp Bot. 2014;107:71-83.

26. Harada T, Torii Y, Morita S, Onodera R, Hara Y, Yokoyama R, et al. Cloning, characterization, and expression of xyloglucan endotransglucosylase/hydrolase and expansin genes associated with petal growth and development during carnation flower opening. J Exp Bot. 2011;62(2):815-23.

27. Li Y, Jones L, McQueen-Mason S. Expansins and cell growth. Curr Opin Plant Biol. 2003;6(6):603-10.

28. Rose JK, Braam J, Fry SC, Nishitani K. The XTH family of enzymes involved in xyloglucan endotransglucosylation and endohydrolysis: current perspectives and a new unifying nomenclature. Plant Cell Physiol. 2002;43(12):1421-35.

29. Strohmeier M, Hrmova M, Fischer M, Harvey AJ, Fincher GB, Pleiss J. Molecular modeling of family GH16 glycoside hydrolases: potential roles for xyloglucan transglucosylases/hydrolases in cell wall modification in the poaceae. Protein Sci. 2004;13(12):3200-13.

30. Eklöf JM, Brumer H. The XTH gene family: an update on enzyme structure, function, and phylogeny in xyloglucan remodeling. Plant Physiol. 2010;153(2):456-66.

31. Johansson P, Denman S, Brumer H, Kallas AM, Henriksson H, Bergfors T, et al. Crystallization and preliminary $\mathrm{X}$-ray analysis of a xyloglucan endotransglycosylase from Populus tremula x tremuloides. Acta Crystallogr Sect D. 2003:59(3):535-7.

32. Michailidis G, Argiriou A, Darzentas N, Tsaftaris A. Analysis of xyloglucan endotransglycosylase/hydrolase (XTH) genes from allotetraploid (Gossypium hirsutum) cotton and its diploid progenitors expressed during fiber elongation. J Plant Physiol. 2009;166(4):403-16.

33. Behar H, Graham SW, Brumer H. Comprehensive cross-genome survey and phylogeny of glycoside hydrolase family 16 members reveals the evolutionary origin of EG16 and XTH proteins in plant lineages. Plant. 2018;95(6):1114-28

34. Miedes E, Lorences EP. Xyloglucan endotransglucosylase/hydrolases (XTHs) during tomato fruit growth and ripening. J Plant Physiol. 2009;166(5):489-98.

35. Song JB, Wang YX, Li HB, Li BW, Zhou ZS, Gao S, et al. The F-box family genes as key elements in response to salt, heavy mental, and drought stresses in Medicago truncatula. Funct Integr Genomics. 2015;15(4):495-507.

36. Xuan Y, Zhou ZS, Li HB, Yang ZM. Identification of a group of XTHs genes responding to heavy metal mercury, salinity and drought stresses in Medicago truncatula. Ecotoxicol Environ Saf. 2016;132:153-63.

37. Yokoyama R, Rose JK, Nishitani K. A surprising diversity and abundance of xyloglucan endotransglucosylase/hydrolases in rice. Classification and expression analysis. Plant Physiol. 2004;134(3):1088-99.

38. Fu M-M, Liu C, Wu F. Genome-wide identification, characterization and expression analysis of Xyloglucan Endotransglucosylase/hydrolase genes family in barley (Hordeum vulgare). Molecules. 2019;24(10):1935.

39. Yokoyama R, Nishitani K. A comprehensive expression analysis of all members of a gene family encoding cell-wall enzymes allowed us to predict cis-regulatory regions involved in cell-wall construction in specific organs of Arabidopsis. Plant Cell Physiol. 2001;42(10):1025-33.

40. Cho SK, Kim JE, Park JA, Eom TJ, Kim WT. Constitutive expression of abiotic stress-inducible hot pepper $\mathrm{CaXTH} 3$, which encodes a xyloglucan endotransglucosylase/hydrolase homolog, improves drought and salt tolerance in transgenic Arabidopsis plants. FEBS Lett. 2006;580(13):3136-44.

41. Sasidharan R, Chinnappa C, Staal M, Elzenga JTM, Yokoyama R, Nishitani K, et al. Light quality-mediated petiole elongation in Arabidopsis during shade avoidance involves cell wall modification by xyloglucan endotransglucosylase/hydrolases. Plant Physiol. 2010;154(2):978-90.

42. Yang JL, Zhu XF, Peng YX, Zheng C, Li GX, Liu Y, et al. Cell wall hemicellulose contributes significantly to aluminum adsorption and root growth in Arabidopsis. Plant Physiol. 2011;155(4):1885-92.

43. Choi JY, Seo YS, Kim SJ, Kim WT, Shin JS. Constitutive expression of CaXTH3, a hot pepper xyloglucan endotransglucosylase/hydrolase, enhanced tolerance to salt and drought stresses without phenotypic defects in tomato plants (Solanum lycopersicum cv. Dotaerang). Plant Cell Rep. 2011;30(5):867-77.
44. Tang Q, Ma X, Mo C, Wilson IW, Song C, Zhao H, et al. An efficient approach to finding Siraitia grosvenorii triterpene biosynthetic genes by RNA-seq and digital gene expression analysis. BMC Genomics. 2011;12:343.

45. Chao Q, Gao ZF, Zhang D, Zhao BG, Dong FQ, Fu CX, et al. The developmental dynamics of the Populus stem transcriptome. Plant Biotechnol J. 2019;17(1):206-19.

46. Hao da C, Ge G, Xiao P, Zhang Y, Yang L. The first insight into the tissue specific taxus transcriptome via Illumina second generation sequencing. PLoS One. 2011;6(6):e21220

47. Sadat-Hosseini M, Bakhtiarizadeh MR, Boroomand N, Tohidfar M, Vahdati K. Combining independent de novo assemblies to optimize leaf transcriptome of Persian walnut. PLoS One. 2020;15(4):e0232005.

48. Furtado BU, Nagy I, Asp T, Tyburski J, Skorupa M, Gołębiewski M, et al. Transcriptome profiling and environmental linkage to salinity across Salicornia europaea vegetation. BMC Plant Biol. 2019;19(1):427.

49. Ma YJ, Duan HR, Zhang F, LiY, Yang HS, Tian FP, et al. Transcriptomic analysis of Lycium ruthenicum Murr. during fruit ripening provides insight into structural and regulatory genes in the anthocyanin biosynthetic pathway. PLoS One. 2018;13(12):e0208627.

50. LüX-P, Gao H-J, Zhang L, Wang Y-P, Shao K-Z, Zhao Q, et al. Dynamic responses of Haloxylon ammodendron to various degrees of simulated drought stress. Plant Physiol Biochem. 2019;139:121-31.

51. Gordon SP, Tseng E, Salamov A, Zhang J, Meng X, Zhao Z, et al. Widespread Polycistronic transcripts in Fungi revealed by single-molecule mRNA sequencing. PLoS One. 2015;10(7):e0132628.

52. Kanehisa M. KEGG bioinformatics resource for plant genomics and metabolomics. Methods Mol Biol. 2016;1374:55-70.

53. Lamesch P, Berardini TZ, Li D, Swarbreck D, Wilks C, Sasidharan R, et al. The Arabidopsis information resource (TAIR): improved gene annotation and new tools. Nucleic Acids Res. 2011;40(D1):D1202-10.

54. Letunic I, Bork P. 20 years of the SMART protein domain annotation resource. Nucleic Acids Res. 2017;46(D1):D493-6.

55. Finn RD, Clements J, Eddy SR. HMMER web server: interactive sequence similarity searching. Nucleic Acids Res. 2011;39(Web Server issue):W29-37.

56. Tamura K, Peterson D, Peterson N, Stecher G, Nei M, Kumar S. MEGA5: molecular evolutionary genetics analysis using maximum likelihood, evolutionary distance, and maximum parsimony methods. Mol Biol Evol. 2011:28(10):2731-9.

57. Larkin MA, Blackshields G, Brown NP, Chenna R, McGettigan PA, McWilliam $\mathrm{H}$, et al. Clustal W and Clustal X version 2.0. Bioinformatics. 2007;23(21):2947-8.

58. Bailey TL, Johnson J, Grant CE, Noble WS. The MEME suite. Nucleic Acids Res. 2015;43(W1):W39-49.

59. Bustin SA, Benes V, Garson JA, Hellemans J, Huggett J, Kubista M, et al. The MIQE guidelines: minimum information for publication of quantitative realtime PCR experiments. Clin Chem. 2009;55(4):611-22.

60. Xiao X, Ma J, Wang J, Wu X, Li P, Yao Y. Validation of suitable reference genes for gene expression analysis in the halophyte Salicornia europaea by realtime quantitative PCR. Front Plant Sci. 2015:5:788.

61. Livak KJ, Schmittgen TD. Analysis of relative gene expression data using real-time quantitative PCR and the $2\left({ }^{-\triangle \triangle} \mathrm{C}_{(\mathrm{T})}\right)$ method. Methods. 2001;25(4):402-8

62. Baumann MJ, Eklöf JM, Michel G, Kallas AM, Teeri TT, Czjzek M, et al. Structural evidence for the evolution of xyloglucanase activity from xyloglucan endo-transglycosylases: biological implications for cell wall metabolism. Plant Cell. 2007;19(6):1947-63.

63. Li Q, Li H, Yin C, Wang X, Jiang Q, Zhang R, et al. Genome-wide identification and characterization of Xyloglucan Endotransglycosylase/hydrolase in Ananas comosus during development. Genes. 2019;10(7):537.

64. Schimenti JC, Duncan CH. Ruminant globin gene structures suggest an evolutionary role for Alu-type repeats. Nucleic Acids Res. 1984;12(3):1641-55.

65. Campbell P, Braam J. Xyloglucan endotransglycosylases: diversity of genes, enzymes and potential wall-modifying functions. Trends Plant Sci. 1999:4(9):361-6.

66. Clauw P, Coppens F, De Beuf K, Dhondt S, Van Daele T, Maleux K, et al. Leaf responses to mild drought stress in natural variants of Arabidopsis. Plant Physiol. 2015;167(3):800-16.

67. Wu Y, Jeong B-R, Fry SC, Boyer JS. Change in XET activities, cell wall extensibility and hypocotyl elongation of soybean seedlings at low water potential. Planta. 2005;220(4):593-601. 
68. Tenhaken R. Cell wall remodeling under abiotic stress. Front Plant Sci. 2015;5:771.

\section{Publisher's Note}

Springer Nature remains neutral with regard to jurisdictional claims in published maps and institutional affiliations.

- fast, convenient online submission

- thorough peer review by experienced researchers in your field

- rapid publication on acceptance

- support for research data, including large and complex data types

- gold Open Access which fosters wider collaboration and increased citations

- maximum visibility for your research: over 100M website views per year

At BMC, research is always in progress.

Learn more biomedcentral.com/submissions 